\section{Comment on 'Midwives' experiences and views of giving postpartum contraceptive advice and providing long-acting reversible contraception: a qualitative study'}

We thank McCance and Cameron ${ }^{1}$ for their article on midwives' experiences and views on postpartum contraception and for highlighting an often neglected aspect of maternity care. The midwives interviewed by McCance were generally not very positive about their ability to make a difference.

We would like to describe a positive experience and the approach used in our work with vulnerable families.

There is no current best practice for promoting and providing postpartum contraception. However, we feel that new mothers are in a health care environment and are open to receiving information about reproductive health. Estrogen-containing contraceptives and intrauterine methods are United Kingdom Medical Eligibility Criteria (UKMEC) Category 3 in the postpartum period. Diaphragms and cervical caps are also not suitable. Contraceptive options are thus limited to progestogen-only methods and condoms. Oral progestogen-only methods can be started following discharge from the ward. The only contraceptive options that should be started prior to discharge are those that women cannot initiate themselves, namely progestogen injections or contraceptive implants. Contraceptive implants are effective, safe and one of the most cost-effective contraceptive options available. Offering contraceptive implants to teenagers in the postpartum period has been found to be highly cost effective. ${ }^{2}$ Immediate postpartum contraceptive implants are very well tolerated ${ }^{3}$ and retained ${ }^{4}$ and have no effect on lactation and neonatal development. ${ }^{5}$

In practical terms we only had to answer two questions, namely (1) how do we best inform women of the availability of postpartum implants and (2) how do we best make this option available to women who request it?

Every obstetric unit has a health worker specialising in the care of women who are at risk of having their children taken into care, usually a safeguarding midwife. They know the pain caused when children are taken away from their parents, and that frequent pregnancies at brief intervals can result in a cycle of hope and despair. They usually have a good rapport with their patients and are often one of the few health workers that these women trust.

Since January 2014 we have been operating in the following way. The safeguarding midwife discusses contraception with her patients in the antenatal and immediate postpartum periods. In an ideal world the contraceptive implant would be provided by the midwife herself, but complex training requirements make this option less attractive and feasible. The obvious solution is to make other implant providers easily accessible to the midwives. If a patient accepts an implant then the midwife calls a designated implant inserter. At Guy's and St Thomas' we (RP and AV) insert contraceptive implants between clinics on Tuesdays and Fridays, and on demand on other days, when we are in the same building as the obstetric department. The implant provision takes only 15 minutes on the postnatal ward as the patient is certain of her choice, needs only the essential information about the implant, and is generally in good health. Using this approach we protect over $50 \%$ of the patients under the care of the safeguarding midwife from rapid repeat pregnancies and provide on average one implant each week. Of all our activities this is likely to be the most cost-effective and rewarding. Each inserted implant can be expected to be retained for 2 years and will probably prevent $>0.5$ children going through the Family Drugs and Alcohol Court (FDAC), where the cost of one FDAC case is in excess of $£ 50000$. 
An Vanthuyne, MBChB, MFSRH

ST5 in Sexual and Reproductive Health, Guy's and St Thomas' NHS Foundation Trust, London, UK ; an.vanthuyne@gstt.nhs.uk

Geraldine Joyce, RM, RN

Named Midwife for Safeguarding Vulnerable Families, Guy's and St Thomas' NHS Foundation Trust, London, UK; geraldine.joyce@gstt.nhs.uk

Rudiger Pittrof, MSC, MRCOG

Consultant in Sexual Health and HIV, Guy's and St Thomas' NHS Foundation Trust, London, UK; rudiger.pittrof@gstt.nhs.uk

Competing interests None.

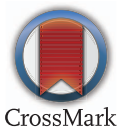

J Fam Plann Reprod Health Care 2014:40:313-314. doi:10.1136/jprhc-2014-101067

\section{REFERENCES}

1 McCance K, Cameron S. Midwives' experiences and views of giving postpartum contraceptive advice and providing long-acting reversible contraception: a qualitative study. J Fam Plann Reprod Health Care 2014;40: 177-183.

2 Han L, Teal SB, Sheeder J, et al. Preventing repeat pregnancy in adolescents: is immediate postpartum insertion of the contraceptive implant cost effective? Am J Obstet Gynecol 2014;211:24.e1-24.e7.

3 Ireland LD, Goyal V, Raker CA, et al. The effect of immediate postpartum compared to delayed postpartum and interval etonogestrel contraceptive implant insertion on removal rates for bleeding. Contraception. Published Online First: 24 May 2014. doi:10.1016/ j.contraception.2014.05.010.

4 Wilson S, Tennant C, Sammel MD, et al. Immediate postpartum etonogestrel implant: a contraception option with long-term continuation. Contraception. Published Online First: 14 May 2014. doi:10.1016/ j.contraception.2014.05.006.

5 Bahamondes L, Bahamondes MV, Modesto W, et al. Effect of hormonal contraceptives during breastfeeding on infant's milk ingestion and growth. Fertil Steril 2013;100:445-450. 